\title{
Framework and service scenarios for smart-work
}

\author{
Kyu Ouk Lee*, Ho Young Song*, Heechang Chung** \\ *ETRI, 218 Gajeongno, Yuseong-gu, Daejeon, Korea \\ **NIA, Bldg 77, Mugyo-Dong, Jung-Gu, Seoul, Korea \\ kolee@etri.re.kr, hsong@etri.re.kr, gyoonchung@hanmail.net
}

\begin{abstract}
The necessity, service categories, and merit points of smart-work were described for smart work implementation. Especially, the call set-up and call release procedure are shown for conference services, along with service scenarios and use case of $\mathbf{A} / \mathrm{V}$ conferencing service in smart-work.
\end{abstract}

\section{Keywords - ICT, DB, DRM, VPN, PDA}

\section{INTRODUCTION}

Smart-work is a pervasive concept using ICT arrangements which employees can work anytime, anywhere with any devices without any limitation in working location and time as shown in Figure 1. [1]

The main merit points of smart works are as follows

- Enhancement of work productivity and customer satisfaction

- Deduction of total expenditure

- Utilization of expert ability

- Enforcement of organization's specialization

- Balance realization of work and life

- Enlargement of working chance

- Decrease of centralization in large city and enhancement of local economics in local city

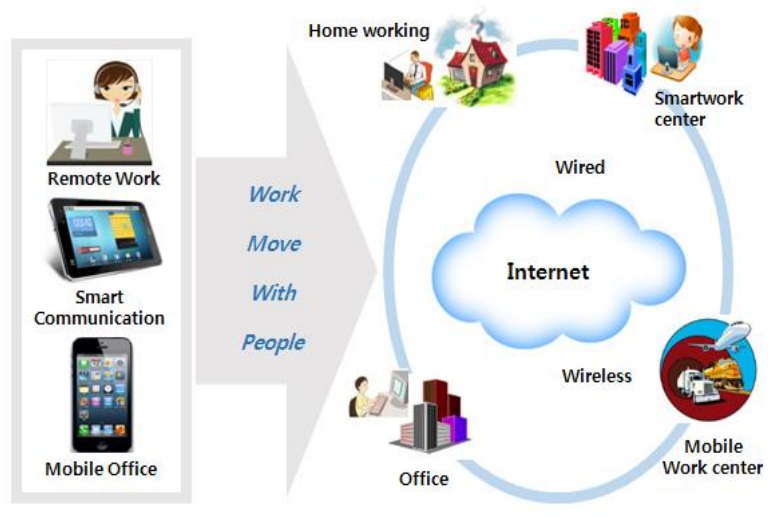

Figure 1. Basic concept of Smart-work environments

\section{TYPE OF SMART-WORK}

Smart-work can be divided into 4 categories; home working, smart-work centre working, mobile work centre working, and office working. The home working is executing any work by providing and utilizing the necessary facilities at home for saving time, space, physical conditions, while smart-work centre working is working at smart centre near home for saving commuting time and promoting creative idea under almost same facility environments as office. The mobile work centre working is carry out any work by using portable sets as smart phone, PDA, I-Pad, note book under mobile networks, and office working is performing any work at office [2] [6].

\section{A. Home working}

The home working is working at home using ICT facilities which was established at cooperate company near home and the interconnection between home user and cooperate company is Internet or mobile network as shown in Figure 2 [3] [6].

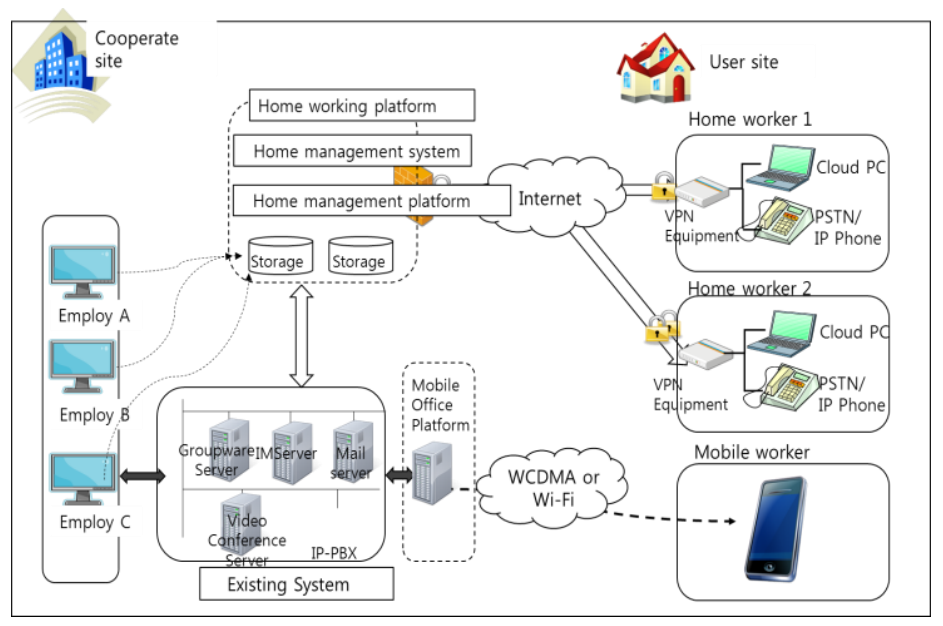

Figure 2. In-house home working service

The basic entities for home working are as follows

- Infrastructure: The infrastructure means ICT equipment as notebook PC, monitor, key board, mouse, scanner, copy machine, and personal web camera for Tele-conference as well as telecommunication networks [4] [6].

- Security: The security is requisite as anti-virus, intrusion protection as firewall, integration PC 
security, DB and DRM content protection, network approaching control, and VPN.

- Accessibility: The necessities are offered as electronic signature, messenger, E-mail, remote cooperation management, etc.

- Management: The necessary management system and data are offered as DMS, PMS, data back-up, personal office equipment.

\section{B. Smart-work center working}

The smart-work center working is working at special place, called "smart-work center" where every ICT facilities were established as official office near household site, and smartwork centre can be divided into 3 categories as follows.

- Public transportation oriented work centre: smart-work centre is installed and operated at train terminal, airport, bus terminal for private or public organizations for public based service

- Business focused work centre: smart-work centre is installed and operated at large building for business man or small venture capital persons.

- Household site oriented work centre: smart-work centre is installed and operated at near house for avoiding traffic congestion and reducing transportation fee during rush hour.

\section{Mobile office working}

The mobile office working is working at anywhere or anyplace using mobile terminals and mobile Internet by connecting to office data, process, and systems as shown in Figure 3 [5].

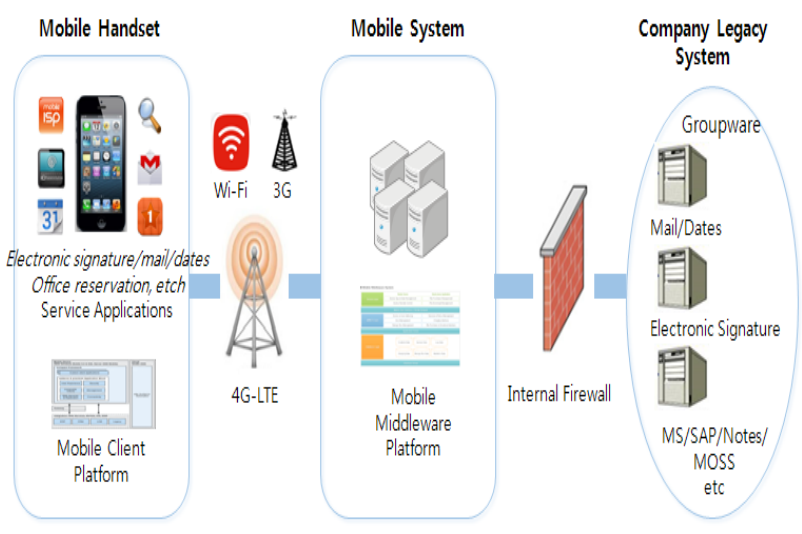

Figure 3. Mobile office working service

\section{SERVICE SCENARIOS OF A/V CONFERENCING SERVICE}

Among the smart-work applications, one of key applications will be high quality $\mathrm{A} / \mathrm{V}$ conferencing system, and there are two kinds of system; SIP based conference service and H.323 based conference service.
Here, only the call set-up and release procedures of H.323 conference service are shown in Figure 4 and Figure 5 [8].

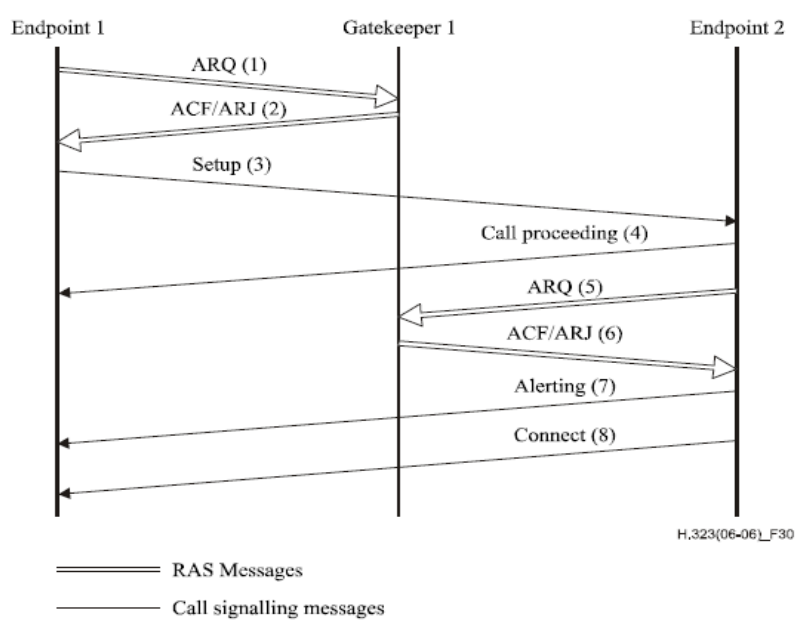

Figure 4. Call set-up procedure of H.323 conference service

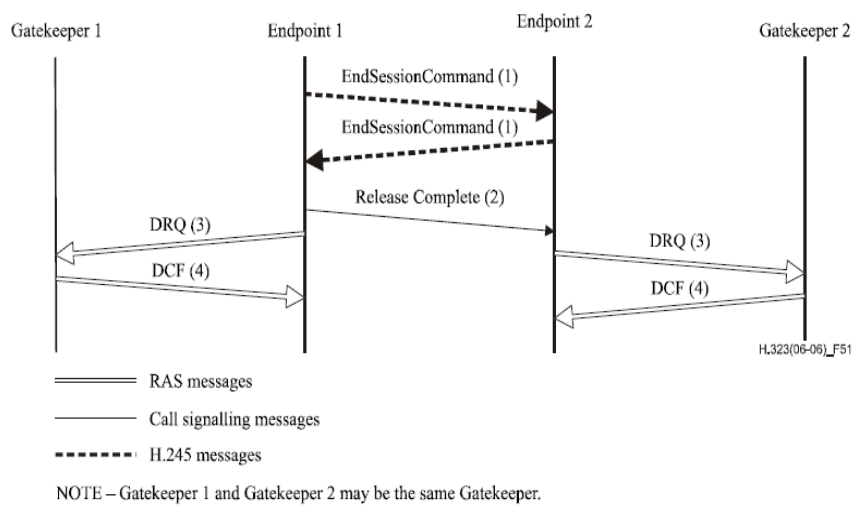

Figure 5. Call release procedure of H.323 conference service

Typically A/V conferencing service can be categorized as follows according to the quality and the way of provisioning [6].

\section{A. Video conferencing}

Video conferencing uses $\mathrm{A} / \mathrm{V}$ telecom. capabilities to connect remote people at different sites. This can be as simple as a conversation between people in private offices (point-topoint) or involve several (multipoint) sites in large rooms at multiple locations. Besides the audio and visual transmission, collaboration capabilities for instance sharing documents, exchanging messages and sharing whiteboards are accompanied. Video conferencing system can be installed in dedicated system or general-purposed system. Usually this video conferencing service is provided on generic network [4]

- Dedicated systems have all required components packaged into a single piece of equipment, usually a 
console with a high quality remote controlled video camera.

- General-purposed systems (Desktop PC) are add-ons to normal personnel computers, transforming them into video conferencing devices.

\section{B. Telepresence conferencing}

Telepresence refers to a set of technologies which allow a person to feel as if they were present, to give the appearance of being present, or to have an effect at a place other than their true location. This service usually requires QoS guaranteed network, for instance, enterprise network.

Nowadays requirements for more capabilities and fewer restrictions at a significantly lower cost than traditional bridging hardware drive cloud-based video conferencing system. While, the high level architecture of Telepresence conference service is shown in Figure 6 [7].

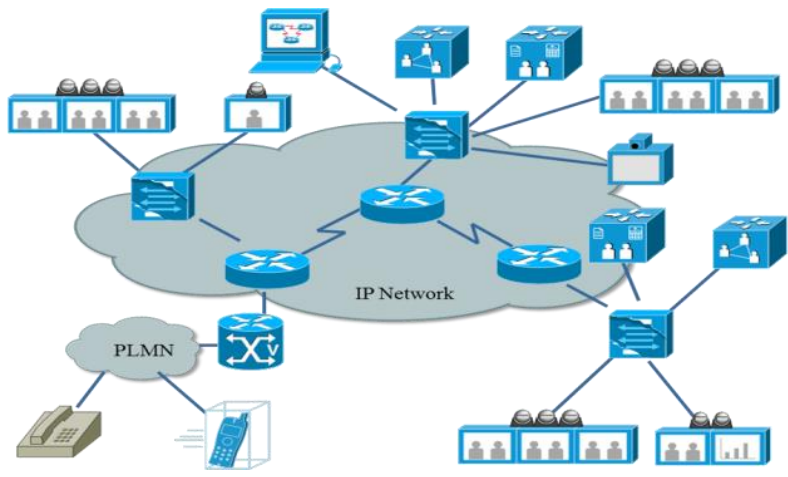

Figure 6. High level architecture of Telepresence conference service

\section{USE CASE OF A/V CONFERENCING SERVICE}

$\mathrm{A} / \mathrm{V}$ conferencing service can be divided into Web conference, video conference, Telepresence service.

Videoconferencing uses $\mathrm{A} / \mathrm{V}$ telecommunications capabilities to connect remote people at different sites. This can be as simple as a conversation between people in private offices (point-to-point) or involve several (multipoint) sites in large rooms at multiple locations. Besides the audio and visual transmission, collaboration capabilities for instance sharing documents, exchanging messages and sharing whiteboards are accompanied. Video conferencing system can be installed in dedicated system or general-purposed system. Usually this video conferencing service is provided on generic network.

- Dedicated systems have all required components packaged into a single piece of equipment, usually a console with a high quality remote controlled video camera.

- General-purposed systems (Desktop PC) are add-ons to normal PCs, transforming them into videoconferencing devices.

And, Telepresence service refers to a set of technologies which allow a person to feel as if they were present, to give the appearance of being present, or to have an effect at a place other than their true location. This service usually requires QoS guaranteed network, for instance, enterprise network. The typical use case of Web conference, video conference, Telepresence are shown in Figure 7 [6]
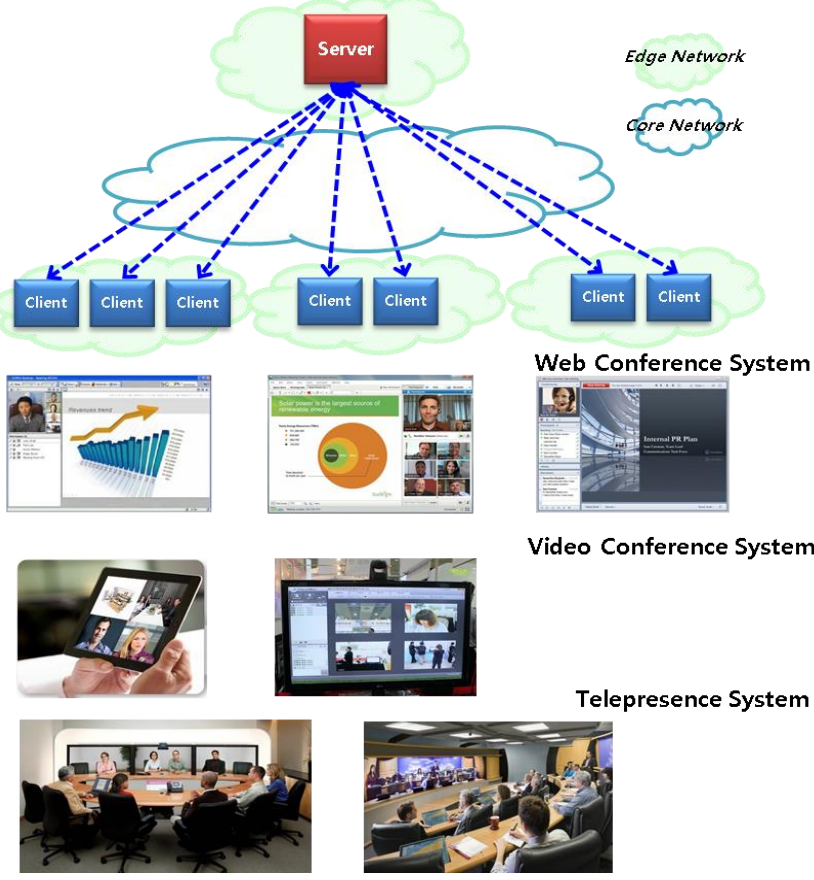

Figure 7. Use case of $\mathrm{A} / \mathrm{V}$ conferencing service

\section{CONCLUSIONS}

The home working, smart-work center working, mobile office working, video and Telepresence conference are described for smart-work implementation, along with the necessity and merit points of smart-work. Especially, the service scenarios and use case of $\mathrm{A} / \mathrm{V}$ conferencing service are mentioned for remote-site workers, along with the call set-up and call release procedure in smart-work. These scenarios and use cases can became useful guidelines for implementation of smart-work in near future.

\section{REFERENCES}

[1] Broadcasting and Telecommunication committee \& National Information Agency, The introduction and operation guidebook of smart-work for cooperate company, 2011.

[2] Information Telecommunication policy Research, Current status and propagation method of smart-work, 2010.

[3] Economics and management research in Korea Telecom., Introduction policy and innovation method of smart-work and mobile office, 2011.

[4] Economics and management research in Korea Telecom., The status and propagation project of Teleworking, 2010.

[5] W. Hyun, S.G. Kang, Standardization trends and smart-work - Focused on telepresence, 2011.

[6] TD124-Y.fsn, ITU-T SG13, New draft Supplement Y.fsn, Framework and service scenarios for smart-work, November 2013.

[7] TD8-F/H. TPS-Arch, ITU-T SG16, Telepresence system architecture, January, 2013

[8] Joo Young Park, ICT Forum Korea, Standardization trends of smartwork core technologies, Sept, 2013 

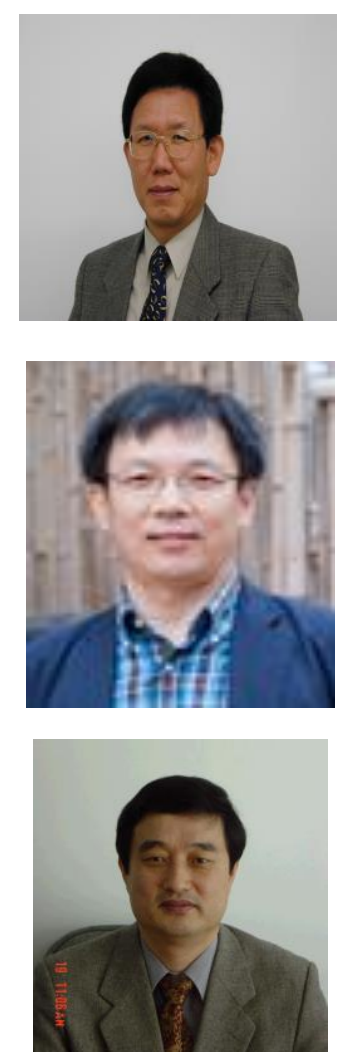

Kyu Ouk Lee

Kyu Ouk Lee received B.S degree from Korean Aviation University, Korea in 1980, M.S degree from Northern Illinois University, America in 1990. His current research interests include network design, optic module, and standardization. Currently he is a special fellow in ETRI, president of Multi Service Forum and Editor in ITU-T SG 13 Standardization.

\section{Ho Young Song}

Ho-Young Song is currently working as the director of Research Planning Team for Communications \& Internet in ETRI, Korea. He received $\mathrm{PhD}$. degrees from Chungbuk National University in Korea. His recent research interests include Information Centric Networking, Cloud networking, SW Defined Networking and future internet technologies.

\section{Heechang Chung}

Heechang Chung received B.S degree from Korea University, Korea in 1980, M.S and P.H degree from Aju University, Korea in 1989 and 1997. His current research interests include network management, service scenario creation and standardization. Currently he is a special fellow in NIA, a Rapporteur in ITU-T SG13 Standardization. 